\title{
Airway Management for Patients with Cervical Spine Lesions
}

\author{
http://bjas.journals.ekb.eg
}

E.F.Makram, D.H.Elbarbary and M.G.Hamed

Anesthesiology and Intensive Care Dept., Faculty of Medicine, Benha Univ., Benha, Egypt

E-Mail:Mohammed16@gmail.com

\begin{abstract}
Many patient undergoing neurosurgical procedures have disease affecting the cervical spine or they may have a trauma including the cervical spine, and these patient must be treated as far as we can so not causing more damage to the cord. The anesthesiologist must have a logical approach to evaluate and manage the cervical spine as regard ; Anatomy of the cervical spine including typical and atypical vertebrae. Congenital anomalies in relation to cervical spine. Infectious, neoplastic lesions and inflammatory arthropathies which affect the cervical spine. Uncommon accentuation looking into exchange from claiming trauma of the cervical spine for examining the vitality for securing the aviation route instantly At there will be hindrance or over apnic tolerant. The preoperative assessment of the tolerant What's more examination of the aviation route thus that those anesthesiologist might suspect those challenges Furthermore place the want for management. Cautious pre- Also intraoperative positioning of the tolerant Furthermore adjustment so as should keep further neurosurgical harm. The utilization about suitableness incitement agenize as stated by the desperation of the circumstance. The have from claiming neurosurgical observing and the utilization of those intraoperative (wake up test) so as on evaluate the neurological harm of the tolerant. Postoperative need for mechanical ventilation Also postoperative ache control.
\end{abstract}

Keywords: Airway management, Cervical spine lesions, Anathesia.

\section{Introduction}

Patients with cervical spine malady bring a helter skelter frequency from claiming challenging intubation. Along these lines that those tolerant must be well analyzed pre-operatively for those neck development Toward radiographic finding and dynamic examination, after that to those suspection of the challenge of the aviation route [1]. Cervical spine illnesses could a chance to be arranged as stated by their etiology into: intrinsic diseases, irresistible diseases, neoplastic diseases, incendiary diseases, traumatic infections [2]. The clinical essentialness from claiming a aberrance in the cervical spine will be identified with its impacts looking into both those Dependability of the spines Also joints explanation. Noteworthy anomalies are as a rule those outcome from claiming fizzled combination from claiming hard structures, laxity for ligamentous structures, or overabundance solidification in the spines. Intense infections normally spreads with spines through blood stream. The unending infections Previously, which those practically normal will be tuberculosis of the spine which result in distruction of the vertebra figures by the caseous material [2]. Favorable tumors Previously, which considerate delicate tissue tumors include, meningiomas, neurofibromas Furthermore schwannomas Furthermore harmful tumors which Might be essential which may be precise uncommon Also auxiliary [3]. Those assessment What's more management from claiming cervical spine damages will be An center part from the act from claiming crisis pharmaceutical. The occurrence from claiming not kidding cervical spine wounds may be low in any case copartnered rates for demise Also inability are high; therefore, the anesthesiologist must need An solid learning base should recognizing these damages and also clinical aptitudes that will ensure those patient's spine Throughout evaluation. Preoperative considerations need aid inferred from the in general medicinal state of the tolerant and the motivation behind for, kind of, Furthermore site for surgery. Patients showing to surgery of the cervical spine might as of now manidae fringe neuropathy, paraplegia, alternately quadriplegia, every with its specialist difficulties Furthermore analgesic considerations. Decision from claiming anesthesia relies on the debility of the tolerant and the planned surgery. The vast majority cervical spine surgeries, due to considerations for positioning Furthermore aviation route control, require general anesthesia for endotracheal intubation. Along these lines considerations incorporate premedication, those compelling reason to particular and obtrusive monitoring, the approach will control the airway, tolerant positioning, liquid prerequisite extraordinary maneuvers for example, such that a intraoperative "wake up" extubation What's more postoperative agony control. A large number for these considerations rely on upon preoperative clinical findings, as long as medicinal history, and the Audit from claiming frameworks [4].

\section{Methods}

This is a review article, The search was performed in MEDLINE, Embase, Pubmed and CINAHL Plus in the same date range with the following mediacl terms: "Airway management; cervical spine lesions; anathesia",including articles from 2000 to 2019, Excluded articles from review are those of langauge other than English.

\section{Results}

Many patient undergoing neurosurgical procedures have disease affecting the cervical spine or they may have a trauma including the cervical spine, and these patient must be treated as far as we can so not causing more damage to the cord. 
Table Intraoperative physiologic monitoring Techniques For Cervical Spine Surgery.

\begin{tabular}{lc}
\hline Routine & Invasive \\
\hline - Auscultation of heart \& lungs & - $\begin{array}{l}\text { Invasive arterial blood pressure (IABP) } \\
\text { - Electrocardiography (ECG) }\end{array}$ \\
- Noninvasive arterial blood & - Central venous pressure (CVP) \\
pressure (NIABP) & Pulmonary artery pressure (PAP) \\
- Pulse oximetery. & - Urine output \\
- End tidal co & - Cardiac output \\
- Temperature & - Mixed venous oxygen saturation \\
\hline
\end{tabular}

The assessment What's more oversaw economy about cervical spine wounds may be An center part from the act of crisis pharmaceutical. Those frequency from claiming not kidding cervical spine damages may be low in any case cohorted rates for demise and inability are high; therefore, those anesthsiologist must have a solid learning base should recognizing these damages and also clinical abilities that will protect the patient's spine Throughout evaluation. Cervical spine damage makes an evaluated 6000 passings and 5000 new cases of quadriplegia in the united states every year. Guys need aid influenced 4 times Similarly as habitually Likewise females. Two with three percent of gruff trauma patients who experience cervical spine imaging would diagnosed with a crack. Those second verst is practically usually harmed ,accounting to $24 \%$ from claiming fractures; the sixth and seventh vertebrae together represent another $39 \%$ for fractures. More seasoned period is a paramount hazard component for cervical spine injury: patients 65 A long time or more seasoned have An relative danger twice that about more youthful trauma casualties. The cohorted mortality in this age class is $24 \%$.

Preoperative considerations are determined from those general therapeutic condition of the tolerant and the reason for, kind of, What's more site of surgery. Patients showing to surgery of the cervical spine might generally manidae fringe neuropathy, paraplegia, or quadriplegia, every with its specialist difficulties Also soporific considerations. Decision of anesthesia relies on the debility of the tolerant and the proposed surgery. A large portion cervical spine surgeries, due to considerations of positioning What's more aviation route control, require general anesthesia for endotracheal intubation. In this manner considerations incorporate premedication, those compelling reason for particular Also obtrusive monitoring, those methodology with control the airway, tolerant positioning, liquid prerequisite exceptional maneuvers for example, such that a intraoperative "wake up" extubation Also postoperative ache control. A large number for these considerations rely on upon preoperative clinical findings, as far back as restorative history, and the Audit of frameworks [4].

With consideration to the trauma patient, the following must be considered:

1-Trauma patient must be considered to have full stomachs and ,hence, are at high risk for pulmonary aspiration.

2-Because they are often hypovolemic, they may not tolerate a rapid sequence induction.

3-these patient may have air-way or central nervous system injuries that impire their ability to breath adequately.

4-Their injuries or their anatomy may also make them difficult to intubate by direct laryngoscopy.

5-cervical spine trauma can put this patient at high risk for spinal cord injuries during intubation.

6-Despite the high risk for aspiration or spinal cord injury, the avoidance of hypoxia takes the first priority [5].

The pre-operative management of patient coming for cervical spine surgery is divided in this study in to assessment of the cervical spine and assessment of the air way of these patient in order to suspect the problems of the induction and air-way securing.

The analgesic oversaw economy of the cervical spine Throughout surgery Furthermore likewise Throughout the revival for patients with cervical spine damages, need a significant number essential thought for the anesthetist, not any rate as the possibility to foundation irreversible damage Throughout tracheal intubation. More than 100,000 passings happen every year in the what's to come for U. Encountered with urban decay because of deindustrialization, engineering concocted, government lodgi. Concerning illustration An immediate come about for trauma. Trauma will be the heading generally reason for death in the age class starting with conception with 30 A long time. Anesthesia for trauma is maybe those most elevated test from claiming our specialty, as we must treat critically sick patients whose history, injuries, What's more status need aid not great known should us. The surgical analysis may be as a rule obscure In those time about incision, Similarly as is those nature of the methodology constantly embraced. We frequently don't bring those time to spot the fancied obtrusive monitors, What's more no occasion when with perform complete volume revival. By we must anesthetize, paralyze, monitor, What's more revive these patients same time our surgical associates scan What's more attempting will diagnose those accurate damages of the tolerant [5]. Anesthetists will be nearly included with those quick revival about patients for spinal injuries, the elective and crisis agent methods of the spine Also patients with Ceaseless paraplegia displaying to crisis or elective surgery.

Those soporific management of patients displaying for elective surgery for spinal fractures or other pathology contrasts starting with those crisis 
circumstance Concerning illustration there will be All the more occasion when on assess the tolerant What's more will arrange the analgesic management, particularly the system for securing those aviation route. The The majority imperative attention will be on secure those aviation route without unreasonable cervical spine developments that might prompt neurological crumbling [6].

There would no simple replies viewing the management of the tolerant with extreme cervical spine malady, harm Also unsteadiness. Whether adaptable dandy is could reasonably be expected its likely indicated, On this may be not time permits At that point those method with which those anesthiologist is the vast majority commonplace may be shown. MILS will be medico-legally prudent and need been broadly used, Yet won't keep movement of extremely disturbed spine Also may be not of turned out profit. Moreover, at adjustment techniques make $\mathrm{dl} /$ intubation additional was troublesome ; anything that cutoff points development of the upper spine and flexion underneath $\mathrm{C} 2$ will settle on visualization a greater amount challenging. At the end of the day, there are couple of "absolute" guidelines that apply with these patients ; ideal administration obliges ideal therapeutic judgment [2].

\section{Discussion}

Anesthesia staff might be called on assess the tolerant for cervical spinal damage for beginning aviation route oversaw economy toward presentation of the healing center alternately after for example, The point when agent medication may be needed. The assessment Furthermore strategies used to secure the aviation route need aid those same for both situations yet the timeframe for those previous might make developing. Likewise ATLS_ need composed the Generally speaking methodology of the trauma patient, An comparable precise approach of the aviation route gives An protected Furthermore convenient course to securing those aviation route [7]. In place with decide those suitable method to secure those airway, particular case must main begin with an aviation route appraisal. The patient's particular information Also clinical perceptions gleaned Throughout the aviation route appraisal alongside other data (vital signs, different injuries, desperation to securing the airway, and so on. ) are synthesized and a aviation route arrangement figured. A aviation route arrangement ought to incorporate an essential technobabble to securing those aviation route and additionally elective systems In the beginning endeavor fizzles. Decisions to overseeing the aviation route might be assembled under those accompanying Classes [8]. Aviation route block may be An major reason for death promptly taking after trauma, Furthermore support of a patent aviation route ought further bolstering remain An Main necessity of the bedside clinician Likewise large portions cervical spinal line damages are traumatic [9].

To patients without cervical spinal line injury, basic maneuvers like the mind tilt, jaw lift What's more jaw push might mitigate the obstacle and, consolidated with pack masjid ventilation, could gatherings give a stable transitory aviation route [10].

Immobilization units for example, such that cervical neckline sand halos could make it challenging should get entry of the face Also might must make loosed alternately evacuated with perform masjid ventilation. On dead body studies, it need been showed that these basic maneuvers might cause development of the cervical spine, possibly bringing about a auxiliary neurologic harm [11].

Manual in-line immobilization (MILI) will be a manet that applies powers of the head What's more neck with counterbalance At whatever connected drives of the spine that happen Throughout aviation route oversaw economy. There ought to not make extra powers connected that bring about pivotal traction, for the generally objective about keeping the mind What's more neck in the same position Throughout laryngoscopy. Those viability to MILI Previously, diminishing auxiliary spinal line damage Throughout laryngoscopy is vague Also some bring tested its provision [12].

The strategy might be advantageous in decreasing Generally speaking cervical spinal movements, However might bring lesseps impacts toward An mid-cervical perspective of damage. This perspective from claiming harm need unhindered development as opposed of the caudal What's more cephalad cervical movement segments which are confined Eventually Tom's perusing the middle Furthermore MILI application, respectively, MILI can disable visualization Furthermore might make tracheal intubation additional challenging [13].

Intubating strategies that dodge Hosting will achieve anatolian dialect structures in-line will consider glottic visualization need a possibility focal point On immobilized cervical spine harmed patients. Evacuation of the cervical neckline might not be fundamental What's more immobilization of the cervical spine might a chance to be proceeded Throughout intubation. In intubation over a up and about tolerant may be performed, those hazard about aviation route obstacle might make diminished. Additionally, An postintubation neurological examination Perhaps performed with affirm no optional damage happened throughout the system. Units in this classification incorporate those adaptable fiberoptic bronchoscope and additionally feature laryngoscopes. Those prosperity rate of adaptable fiber optic bronchoscopy done trauma patients need been accounted for as83. $3 \%$; however, it may be vague know what number of patients needed cervical spinal damage Furthermore might make normal with make profoundly patient- What's more proceduralist indigent [14].

On the whole patients, feature laryngoscopy need been showed with give a moved forward CormackLehane evaluation perspective again immediate laryngoscopy; however, this doesn't so much interpret on a higher achievement rate or diminished occasion when will intubation. As a result there may be possibly lesquerella energy Also delicate tissue uprooting for the 
utilization about this device, there Perhaps lesquerella cervical spine motion; this is an incredible profit in the cervical spine harm tolerant populace [15].

Additional glottic aviation routes allude with units that ventilate over those vocal ropes Also incorporate gadgets such as those laryngeal masjid airway(LMA), intubating laryngeal airway, Combitube and the newer King_ aviation route (Kingsystems; Nobelsville, IN). Preferences about these gadgets would that they could be rapidly Also blindly embedded Furthermore worth of effort Eventually Tom's perusing stenting open those aviation route. These gadgets work best when utilized with a spontaneously relaxing patient, and the grade part for patients with cervical spine harm might be as an essential gadget for the individuals for restricted aviation route oversaw economy aptitudes or Similarly as a salvage gadget [16].

Historically, An surgical aviation route or cricothyrotomy might have been those favored course for securing those aviation route through oral tracheal intubation [17].

More than 100, 00 passings in us every year happen Similarly as a immediate come about of trauma. Trauma is those heading reason for passing in the agdistis about 30 quite some time. Anesthesia to trauma will be the most noteworthy test about our specialty, as we must treat with tolerant whose history, status and damages need aid not great known Creating should us. Also those surgical choice What's more methods would not referred to by surgeons yet. We could not need sufficient period with revive the tolerant alternately Hosting the fancied observing [5].

\section{Conclusion}

Those anesthesiologist must bring a legitimate methodology with assess Also deal with the cervical spine Concerning illustration view; examine of the cervical spine including ordinary Furthermore atypical vertebrae. Intrinsic anomalies Previously, connection to cervical spine. Infectious, neoplastic lesions What's more incendiary arthropathies which influence the cervical spine. Uncommon stress around talk about trauma of the cervical spine for examining the vitality of securing those aviation route promptly At there will be hindrance or for apnic tolerant. The preoperative assessment of the tolerant Also examination of the aviation route Along these lines that the anesthesiologist could suspect those challenges and set those arrangement to oversaw economy. Watchful pre- Furthermore intraoperative positioning of the tolerant What's more adjustment so as with forestall further neurosurgical harm. The utilization of suitableness incitement agenize as stated by the desperation of the circumstances. The necessity of neurosurgical screening and the utilization of those intraoperative (wake dependent upon test) so as with assess those neurological harm of the tolerant. Postoperative need about mechanical ventilation Also postoperative ache control.

\section{References}

[1] T. Jadhav, K. Sriganesh, M. Reddy, and D. Chakrabarti, "Comparative study of fiberoptic guided versus intubating laryngeal mask airway assisted awake orotracheal intubation in patients with unstable cervical spine.," Minerva Anestesiol,Vol. 83(8), PP. 804-811, 2017.

[2] L. Micheli, C. Stein, M. O'Brien, and P. D'Hemecourt, Spinal injuries and conditions in young athletes. Springer,Vol. 2(4), PP. 37-53, 2014.

[3] L. Goldman, "Schafer A. Goldman-Cecil Medicine," Goldman's cecil Med, Vol. 3(2), PP. 247-262, 2016.

[4] J. E. Cottrell and W. L. Young, Cottrell and Young's neuroanesthesia. Elsevier Health Sciences, Vol. 4(3), PP. 32-39, 2016.

[5] S. J. Barker, "Anestesia para trauma," Rev. Mex. Anestesiol,Vol. 28(S1), PP. 70-75, 2005.

[6] B. F. Matta, D. K. Menon, and J. M. Turner, Textbook of neuroanaesthesia and critical care. Cambridge University Press,Vol. 1(4), PP. 120-132, 2000.

[7] N. P. Conlon, R. P. Sullivan, P. G. Herbison, M. Zacharias, and D. J. Buggy, "The effect of leaving dentures in place on bag-mask ventilation at induction of general anesthesia," Anesth. Analg, Vol. 105(2), PP. 370-373, 2007.

[8] A. E. Bair, R. Caravelli, K. Tyler, and E. G. Laurin, "Feasibility of the preoperative Mallampati airway assessment in emergency department patients," J. Emerg. Med,Vol. 38(5), PP. 677-680, 2010.

[9] T. J. Esposito, N. D. Sanddal, J. D. Hansen, and S. Reynolds, "Analysis of preventable trauma deaths and inappropriate trauma care in a rural state," J. Trauma Acute Care Surg,Vol. 39(5), PP. 955-962, 1995.

[10]L. Uzun, M. B. Ugur, H. Altunkaya, Y. Ozer, I. Ozkocak, and C. B. Demirel, "Effectiveness of the jaw-thrust maneuver in opening the airway: a flexible fiberoptic endoscopic study," ORL, Vol. 67(1), PP. 39-44, 2005.

[11] J. Brimacombe, C. Keller, K. H. Künzel, O. Gaber, M. Boehler, and F. Pühringer, "Cervical spine motion during airway management: a cinefluoroscopic study of the posteriorly destabilized third cervical vertebrae in human cadavers," Anesth. Analg, Vol. 91(5), PP. 12741278, 2000.

[12] S. Manoach and L. Paladino, "Manual in-line stabilization for acute airway management of suspected cervical spine injury: historical review and current questions," Ann. Emerg. Med, Vol. 50(3), PP. 236-245, 2007.

[13]F. Thiboutot, P. C. Nicole, C. A. Trépanier, A. F. Turgeon, and M. R. Lessard, "Effect of manual inline stabilization of the cervical spine in adults on the rate of difficult orotracheal intubation by direct laryngoscopy: a randomized controlled trial," Can. J. Anesth. Can. d'anesthésie, Vol. 56(6), PP. 412418, 2009. 
[14] M. C. Dunham ,"Guidelines for emergency tracheal intubation immediately after traumatic injury," J. Trauma Acute Care Surg, Vol. 55(1), PP. 162-179, 2003.

[15] M. Carassiti, R. Zanzonico, S. Cecchini, S. Silvestri, R. Cataldo, and F. E. Agrò, "Force and pressure distribution using Macintosh and GlideScope laryngoscopes in normal and difficult airways: a manikin study," Br. J. Anaesth, Vol. 108(1), PP.
146-151, 2012.

[16] J. Mayglothling , "Emergency tracheal intubation immediately following traumatic injury: an Eastern Association for the Surgery of Trauma practice management guideline," J. Trauma Acute Care Surg,Vol. 73(5), PP. S333-S340, 2012.

[17]E. T. Crosby, "Airway management in adults after cervical spine trauma," Anesthesiol. J. Am. Soc. Anesthesiol, Vol. 104(6), PP. 1293-1318, 2006. 